\title{
SPATIO-TEMPORAL PATTERN EVOLUTION OF NON-POINT SOURCE PHOSPHORUS LOADS IN CHAOHU LAKE BASIN (ANHUI PROVINCE, CHINA) UNDER DIFFERENT LAND USE PATTERNS
}

\author{
XIONG, J. F. ${ }^{1,2}-$ LIN $_{\text {C. }}{ }^{1 *}-$ MIN, M. ${ }^{1}-$ MA, R. H. ${ }^{1}-$ WU, Z. P. ${ }^{3}-$ JIA, J. J. ${ }^{4}$ \\ ${ }^{1}$ Key Laboratory of Watershed Geographic Sciences, Nanjing Institute of Geography and \\ Limnology, Chinese Academy of Sciences, Nanjing 210008, China \\ ${ }^{2}$ School of Geography and Remote Sensing, Nanjing University of Information Science \& \\ Technology, Nanjing 210044, China \\ (e-mail: xjfpanda@163.com; phone: +86-25-8688-2169) \\ ${ }^{3}$ Ministry of Education Key Laboratory of Protection and Development Utilization of Tropical \\ Crop Germplasm Resources, Hainan University, Haikou 570228, China \\ ${ }^{4}$ Enterprise Innovation Center, Jiangsu Academy of Science and Technology for Development, \\ Nanjing 210042, China \\ *Corresponding author \\ e-mail: clin@niglas.ac.cn \\ (Received $2^{\text {nd }}$ Sep 2017; accepted $6^{\text {th }}$ Sep 2018)
}

\begin{abstract}
Non-point source (NPS) pollution is an important source of lake eutrophication, the phosphorus (P) is one of the main elements of NPS pollution, and land use change has an important influence on NPS pollution load. Most previous studies focused on a single phase and did not analyze the internal structure of land use. In this study, six natural river basins such as the Hangbu River Basin were selected as the study area in Chaohu Basin, China. Based on the Sediment Delivery Distributed (SEDD) model, the NPS P load was simulated from 2000 to 2015, and the characteristics of land use change were depth analyzed at the same time to discuss the mechanism of land use pattern on NPS P load under longterm sequence. The main result are as follow: the NPS P load intensity was positively correlated with FL (forest land) area, in the whole study area, the correlation coefficient between NPS load intensity and FL area was 0.67 , and the NPS P load intensity was negatively correlated with arable land (AL), construction land (CL) and wetland (WL) area, and the correlation coefficients were $0.56,0.26$ and 0.14 respectively. On the other hand, the internal structure of land use is also affecting NPS P load, the Fractal Dimension Index Mean (FRAC) was positively correlated with NPS P loss intensity, and the correlation coefficient is 0.56. Compared to the AL, FL and CL are more easily affected by FRAC. The optimization of land use spatial layout plays an important role in alleviating NPS pollution particle state.
\end{abstract}

Keywords: sediment delivery distributed model, landscape index, long-term sequence, wetland, arable land, construction land, forest land

\section{Introduction}

Phosphorus (P) is one of the main nutrients in inland lakes (Naramngam and Tong, 2013; Norton et al., 2012). As the main reason of eutrophication, Non-point source (NPS) P has been proven to be an important cause of bloom (Delpla et al., 2011; Dong et al., 2014; Hoffmann et al., 2009). The surface P is mainly lost by soil erosion in the adsorbed state (Wang et al., 2012). Under the influence of the dramatic change of land use, the ground surface conditions changed significantly, leading to changes in surface runoff characteristics and soil erosion (Hollis, 1975; Hundecha and Bardossy, 2004), 
Furthermore, the temporal and spatial evolution of NPS pollution loads is influenced (Ahearn et al., 2005). Therefore land use change is an important factor of NPS pollution and lake nutrient enrichment (El-Khoury et al., 2015; Haggard et al., 2001). It can be seen that the improvement of lake water environment must be based on optimizing the spatial distribution of the river basin and reducing the NPS pollution. And exploring the internal relation and the influence mechanism between them has become the hot spot in the academic circles together with river basin environmental management department (Ouyang et al., 2013; Recanatesi et al., 2013; Wu et al., 2012b).

There are two types of estimation models for NPS pollution. The first is physical model, such as the Soil Water Assessment Tool (SWAT) and the Annualized Agricultural Non-Point Source model (AnnAGNPS). This kind of model can accurately simulate NPS P loads (Bingner et al., 2003; Kim et al., 2013; Wilson and Weng, 2011), but the model parameters are complicated, and strongly depending on the plot experiment and observation. Therefore, this model is not suitable for large space scale and long time series, and unfavorable to the comparative analysis between different watershed (Bechmann et al., 2009; Yang et al., 2012). Another kind is empirical model, such as the Sediment Delivery Distributed (SEDD) model and the Pollution Loads (PLOADS) model. Empirical model, by contrast, have characteristics of simple data acquisition, wide applicable scope, strong operability and easy to operate. Therefore, it is very suitable for assessing and simulating NPS P loads in the large space scale and long time series (Borrelli et al., 2014; Bu et al., 2008; Lin et al., 2016).

There have been some studies on the relationship between land use and NPS P loads. In the early stage, Garnier et al. (1998) overlaid USLE model and land use type, results show that, compared to other areas, the NPS pollution loads is significantly higher than other area in the animal husbandry and agriculture concentration areas. Later, urban construction land surface runoff is considered to be one of the important reasons to the NPS pollution (Li et al., 2008; Tang et al., 2005). In addition, some scholar's studies found that the bare surface type, like cultivated land and plantation, is an important source of NPS P loads (Ahearn et al., 2005; Catherine et al., 2013). Recently, with the further research, there are different conclusions about the influence of forest land, construction land, and cultivated land on NPS P loads. Jiang et al. (2014) found NPS P loads was negatively correlated with cultivated land and construction land, while it was positively correlated with forest land. However Tasdighi et al. (2017) suggested that phosphorus loads was positively correlated with construction land, was negatively correlated with agricultural land. Kim et al. (2016) found that the phosphorus loads intensity of cultivated land is highest, followed by forest land.

There are many conclusions which have shown that the change of land use caused by human activities affects NPS P loads. However, previous studies have focused on a single phase and did not analyse the internal structure of land use. This leads to differences between the various scholars, particularly, there is a disagreement about the effects of cultivated land, forest land, and construction land on NPS P loads. Therefore, in this paper, the Chaohu Lake Basin, which has the most serious NPS P loads in China, is selected as the study area (Jiang et al., 2014; Kong et al., 2015), and 6 regions were determined according to the main natural rivers into the lake. The SEDD model (Fu et al., 2006; Lin et al., 2016; Taguas et al., 2011) was used to estimate the NPS P loads in Chaohu Lake Basin from 2000 to 2015, and the spatial analysis methods and indicators, which focus on the diversity of spatial and temporal changes of land use and internal structure, are used in the study to analyze the changes of NPS P loads and land use 
pattern under long-term sequence, and then reveals the mechanism of land use mode on the NPS P loads. First, we confirmed the main land types that affect the NPS P loads, and then discussed the effects of different land use types on NPS P loads. Finally the response mechanism of different land use change patterns to NPS P loads is determined, and it can be used to provide scientific and technical support, and data base for spatial optimization of land use for NPS pollution control.

\section{Materials and methods}

\section{Study sites}

Chaohu Lake is one of China's five major fresh water lake, the lake area is $769 \mathrm{~km}^{2}$, normal hydrological year average water depth is $2.69 \mathrm{~m}$, the maximum water depth of $3.77 \mathrm{~m}$ (Wang and Dou, 1998). Chaohu Lake basin is located in central Anhui Province and north of the Yangtze River Delta, the area is $13350 \mathrm{~km}^{2}$, the terrain is mainly plain, mountain is located in the southwest of the basin. Average annual rainfall is $1215 \mathrm{~mm}$, which flood season for $5 \sim 8$ month, precipitation accounts for $51 \%$ of annual precipitation. The agricultural economy is developed in Chaohu Lank basin, which is the main commodity grain production base in China, agricultural land area accounted for $60 \%$ of the basin area, and the agricultural NPS pollution is serious (Yan and Wang, 1998; Zhou and Gao, 2011). According to remote sensing inversion results and river water quality monitoring data, the west lake area water quality serious pollution (Pan et al., 2011; Shang and Shang, 2007), Nanfei River and Pai River total phosphorus input accounted for $60 \%$ of the total pollution loads of rivers into the lake (Wang et al., 2011).

Natural river basin mainly based on the terrain, and the artificial river is less affected by the terrain, so the main six natural rivers into the lake were selected: (1)Zhegao River, (2)Tongyang River, (3)Nanfei River, (4)Pai River, (5)Hangbu River, (6)Baishitian River. Six river basin range preliminarily determined through the analysis of the hydrological Arc SWAT function, counterclockwise number R1 R6 from east to west, and further subdivided is 55 sub-basins (Fig. 1), the study area partition and its basic information such as shown in Table 1.

\section{The land use data source and land use indices}

Land use is divided into six types: (1) forest land (FL); (2) construction land (CL); (3) grass land (GL); (4) wetland (WL); (5) arable land (AL); (6) unutilized land (UL). According to 55 sub-basin, the area and spatial distribution of six land types were analyzed respectively. In order to evaluate the change of landscape characteristics of each sub-basin with time, four landscape indices that can reflect the spatial structure characteristics are selected, included: (1) Contagion index (CONTAG); (2) Fractal Dimension Index Mean, (FRAC); (3) Shannon`s Diversity Index (SHDI); (4) Shannon`s Evenness Index (SHEI). CONTAG is used to measures the degree of aggregation of the same type of patches and is influenced by the number of landscape homogeneity and type. High value shows that the greater the landscape connectivity of the advantages of plaque type exist. FRAC is a fractal pattern index, is obtained by calculation complexity area ratio, the greater the value the more complex landscape shape. SHDI is used to measure the diversity of land use in a given area. The SHDI value increases with the increase of land use type. SHEI indicates the uniformity of the land use type distribution in the area, the closer the value 1, and distribution more uniform. All landscape indices 
are calculated in Fragstats3.3 (Lin et al., 2015; McGarigal and Marks, 1995). To show the change of land use structure and distribution in sub-basin, according to the landscape index changes over time to classify it into five types: (1) gradually increased (GI); (2) gradually decreased (GD)); (3) first increased and then decreased (ID); (4) first decreased and then increased (DI); (5) fluctuation type (FT).

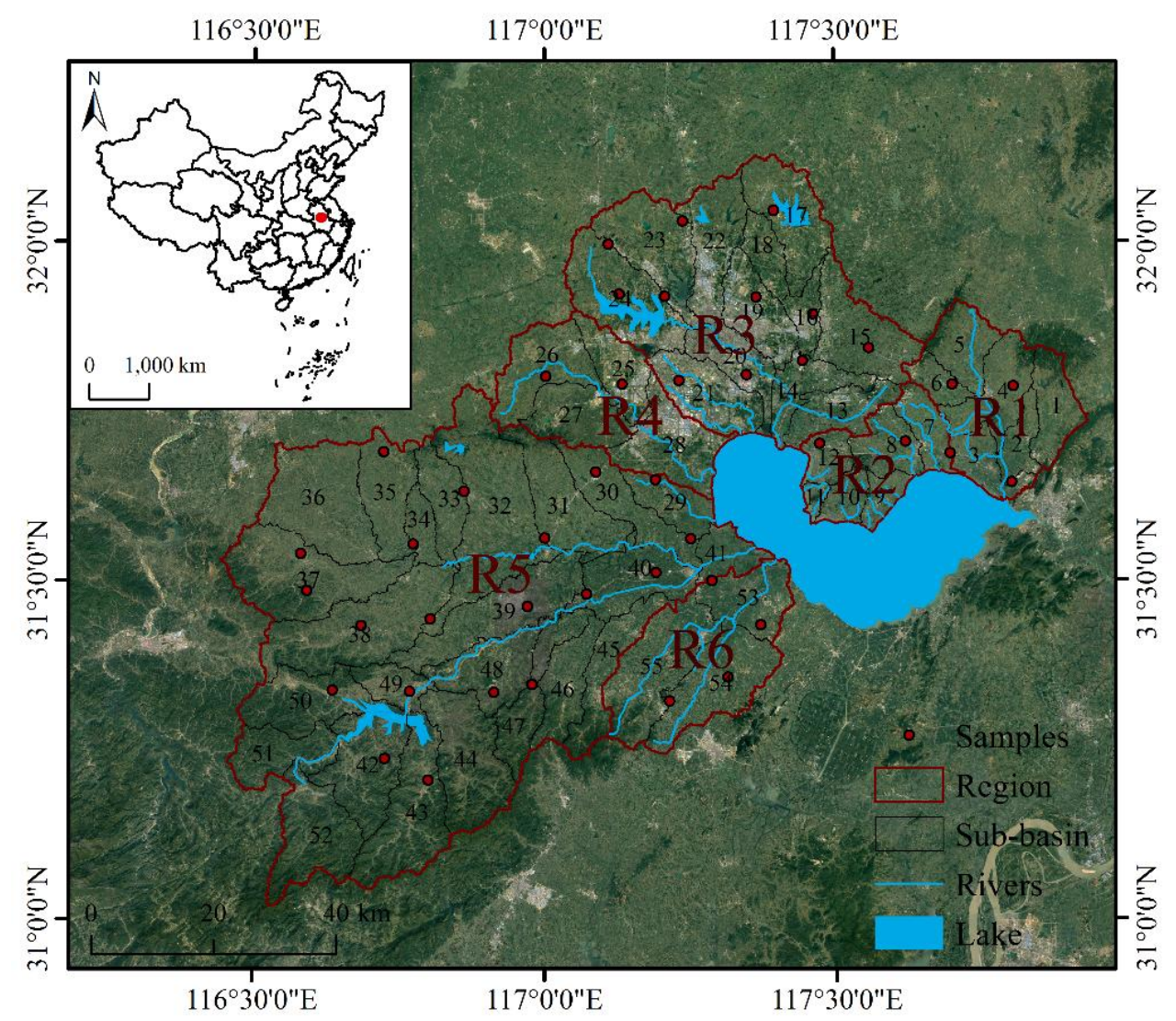

Figure 1. Location of study site and sampling plots

Table 1. Watershed situation of study area

\begin{tabular}{c|c|c|c|c}
\hline Regions & Stream & Sub-basin & Area $\left(\mathbf{k m}^{\mathbf{2}}\right)$ & Administrative unit \\
\hline R1 & Zhegao River & $1 \sim 6$ & 546 & Chaohu City \\
R2 & Tongyang River & $7 \sim 12$ & 350 & Chaohu City, Feidong \\
R3 & Nanfei River & $13 \sim 24$ & 1680 & Hefei City, Feidong \\
R4 & Pai River & $25 \sim 28$ & 603 & Feixi \\
R5 & Hangbu River & $29 \sim 52$ & 4154 & Lu'an City, Feixi, Shucheng, Yuexi \\
R6 & Baishitian River & $53 \sim 55$ & 581 & Lujiang \\
\hline
\end{tabular}

\section{Quantitative evaluation of NPS P loads}

The calculation method of surface phosphorus loads is based on the fundamental form of Revised Universal Soil Loss Equation (RUSLE), the sediment delivery ratio (SDR) and the phosphorus content in the soil, to estimate watershed NPS P loads (Eq. 1; Lin et al., 2016; Yang et al., 2012). 


$$
W=A_{i} \times P \times S D R_{i}
$$

where $W$ is the surface loads of the nutrient substance per unit area per unit area $\left(\mathrm{kg} \cdot \mathrm{km}^{-2} \cdot \mathrm{yr}^{-1)} ; A_{i}\right.$ is the soil erosion amount; $P$ is the soil phosphorus content $\left(\mathrm{g} \cdot \mathrm{kg}^{-1}\right)$; $S D R_{i}$ is the sediment delivery ratio of the grid $i$ (Stefano and Ferro, 2007; Yang et al., 2012; Zhou and Wu, 2008), the equation is (Eq. 2):

$$
S D R_{i}=\exp \left(-\beta t_{i}\right)
$$

where $t_{i}$ is the time required for the loss from the grid $i$ point to the nearest water system, and $\beta$ is a constant. The soil erosion estimation model uses RUSLE as the prototype, and uses the satellite remote sensing technology to provide the data for the model. Therefore, the model calculates the spatial resolution consistent with the satellite remote sensing image, with a $30 * 30 \mathrm{~m}$ grid as the minimum evaluation unit. The model equation is expressed as (Eq. 3):

$$
A_{i}=R_{i} \times L S_{i} \times P_{i} \times C_{i} \times K_{i}
$$

where $R_{i}$ is rainfall erosivity factor $\left(\mathrm{MJ} \mathrm{mm} \cdot(\text { ha } \mathrm{h} \mathrm{yr})^{-1}\right) ; L S_{i}$ is slope length and steepness factor; $P_{i}$ is conservation support practice factor based on land use; $C_{i}$ is cover management factor; $K_{i}$ is soil erodibility factor. $R_{i}$ is based on the monthly rainfall calculation, the calculation method is (Eq. 4):

$$
R_{i}=\sum_{n=1}^{12} 1.735 \times 10^{\left(1.5 \times \lg \left(\frac{P_{i}^{n}}{P}\right)-0.8188\right)}
$$

$P_{i}$ is the average monthly rainfall $(\mathrm{mm})$, and $P$ is the average annual rainfall $(\mathrm{mm}) . L S_{i}$ reflects the topographic factors on the driving force of soil erosion, according to the related literature (Onyando et al., 2005), the calculation method is (Eqs. 5-7):

$$
\begin{gathered}
L=(\lambda / 22.13)^{m} \\
m= \begin{cases}m=0.2 & \theta<0.5^{\circ} \\
m=0.3 & 0.5^{\circ} \leq \theta<1.5^{\circ} \\
m=0.4 & 1.5^{\circ} \leq \theta<3^{\circ} \\
m=0.5 & \theta \geq 3^{\circ}\end{cases} \\
S=\left\{\begin{array}{lr}
10.8 \sin (\theta)+0.03 & \theta \leq 5^{\circ} \\
16.8 \sin (\theta)-0.5 & 5^{\circ}<\theta<10^{\circ} \\
21.9 \sin (\theta)-0.96 & \theta \geq 10^{\circ}
\end{array}\right.
\end{gathered}
$$

where $\theta$ is the slope $\left(^{\circ}\right)$ of the grid $I$ and $\lambda$ is the slope length $(\mathrm{m})$ of the grid in. $P_{i}$ reflects the influence of regional soil and water conservation measures on soil erosion, and its assignment is determined by different land use patterns. The $\mathrm{P}$ was taken on $\mathrm{Xu}$ et al. (2013). 
$C_{i}$ reflects the effect of vegetation on soil erosion, according to Cai et al. (2000) and (Wu et al., 2012a), the calculation method is (Eq. 8):

$$
C= \begin{cases}1, & c=0 \\ 0.6508-0.3436 \lg c, & 0<c \leq 78.3 \% \\ 0, & c>78.3 \%\end{cases}
$$

where $c$ is plant coverage (\%), $K_{i}$ is the soil erodibility, many of the research on the literature research in the study area, assignment of each soil type, interal $(0,1)$. Because the soil types will not change with the passage of time, so we cannot reflect the change characteristics of soil erodibility. In order to reflect the temporal and spatial variability of soil erodibility, the $K_{i}$ values were directly assigned by literature research in 2000 and 2005 (Bu et al., 2002; Zhang et al., 2007), The $K_{i}$ values for 2010 and 2015 are calculated using the initial measurement method specified in the RUSLE equation guide (Eq. 9; Sharpley and Williams, 1990):

$$
\begin{aligned}
K & =\left\{0.2+0.3 \times \exp \left[-0.0256 \times S d \times\left(1-\frac{S l}{100}\right)\right]\right\} \times\left[\frac{S l}{C l+S l}\right]^{0.3} \\
& \times\left\{1.0-0.25 \times \frac{C o c}{C o c+\exp (3.72-2.95 \times C o c)}\right\} \\
& \times\left\{1.0-\frac{0.7 \times(1-S d / 100)}{1-S d / 100+\exp -5.51+22.9 \times(1-S d / 100)}\right\}
\end{aligned}
$$

The model is a function of soil organic matter and mechanical composition, where $\mathrm{Sd}, \mathrm{Sl}, \mathrm{Cl}$, and $\mathrm{Coc}$ correspond to the percentage of soil sand, granule and clay and soil organic carbon.

\section{Sample collection and data acquisition}

Land use classification data sets in 2000, 2005, 2010 and 2015, are provided by the Lake-Watershed Science Data Center, National Earth System Science Data Sharing Infrastructure, National Science \& Technology Infrastructure of China (http://lake.geodata.cn). Land use data supported by the "Strategic Priority Research Program - Climate Change: Carbon Budget and Related Issues" of the Chinese Academy of Sciences, Grant No. XDA05050106.

The soil's physical and chemical properties data were obtained from the laboratory testing which were collected in field (Fig. 1). Surface soil samples $(0 \sim 10 \mathrm{~cm}$ depth) were collected from July 22 to 24, 2016, using four points method according to different land use types: FL, CL and AL. A total of 43 samples were collected and brought back to the laboratory to analyze the physical and chemical properties of the critical soil. The soil total phosphorus (TP), soil organic matter (SOM) and soil particle composition (sand $(0.05 \sim 2 \mathrm{~mm})$, silt $(0.002 \sim 0.05 \mathrm{~mm})$ and clay $(0 \sim 0.002 \mathrm{~mm})$ ) were analyzed after air drying and grinding. TP were measure with inductively coupled plasma-atomic emission spectrometry (ICP-AES). SOM measure with potassium dichromate method. 
The contents of soil particle composition were measured with the pipette method (Lin et al., 2008; Lin et al., 2016). The test results are shown in Table 2.

Table 2. Statistic of soil properties

\begin{tabular}{c|c|c|c|c|c}
\hline & Min & Max & Mean & Std & CV/\% \\
\hline TP $(\mathrm{g} / \mathrm{kg})$ & 0.25 & 2.95 & 0.76 & 0.53 & 70.76 \\
SOM $(\mathrm{g} / \mathrm{kg})$ & 7.41 & 128.77 & 36.08 & 21.94 & 60.80 \\
Clay $(\%)$ & 10.63 & 29.88 & 19.43 & 3.76 & 19.34 \\
Silt (\%) & 42.39 & 81.91 & 72.14 & 7.94 & 11.00 \\
Sand (\%) & 0.41 & 45.15 & 8.43 & 9.80 & 116.19 \\
\hline
\end{tabular}

The spatial representation of each factor of the SEDD model depends on the plot test and the data extraction of the satellite remote sensing image. The basic data needed for each factor are shown in the Table 3.

Table 3. The data source for NPS P loads calculation

\begin{tabular}{c|c|c}
\hline Data type & Data source & Description \\
\hline $\begin{array}{c}\text { Meteorological } \\
\text { Precipitation data } \\
\text { monitoring stations in } \\
\text { Chaohu Basin }\end{array}$ & $\begin{array}{c}\text { The Chaohu Lake Basin has a total of 14 meteorological } \\
\text { monitoring stations, which can get the monthly rainfall data } \\
\text { from } 1970 \text { to the present. After the monthly average and spatial } \\
\text { interpolation, the spatial and temporal distribution of rainfall } \\
\text { erosivity is estimated }\end{array}$ \\
$\begin{array}{c}\text { Digital elevation } \\
\text { model (DEM) }\end{array}$ & $\begin{array}{c}\text { ASTER global DEM } \\
\begin{array}{c}\text { Soil physical and } \\
\text { chemical } \\
\text { properties }\end{array}\end{array}$ & $\begin{array}{c}\text { Downloads the 30 m spatial resolution DEM data from the } \\
\text { USGS site, to calculate the slope length, steepness factor and } \\
\text { SDR }\end{array}$ \\
\hline $\begin{array}{c}\text { Vegetation } \\
\text { coverage }\end{array}$ & $\begin{array}{c}\text { Landsat 5/8 Satellite } \\
\text { imagery }\end{array}$ & $\begin{array}{c}\text { All chemical tests are done in the Key Laboratory of Watershed } \\
\text { Geographic Sciences, Institute of Geography and Limnology, } \\
\text { Chinese Academy of Sciences }\end{array}$ \\
\hline $\begin{array}{c}\text { Soil types } \\
\text { spatial resolution remote sensing images in four years, and } \\
\text { extract the corresponding year vegetation index }\end{array}$ \\
\hline $\begin{array}{c}\text { National soil type } \\
\text { distribution map }\end{array}$ & $\begin{array}{c}\text { After digitizing the national soil type distribution map, } \\
\text { according to the soil type, assigned the soil erodibility factor }\end{array}$ \\
\hline
\end{tabular}

\section{Results}

\section{Characteristics of land use change}

According to the time series, six typical types of land use in the study area were classified. The spatial distribution characteristics of each land use type were shown in Figure 2. The main land use type in the whole basin is the arable land. Forest land is mainly distributed in the southwest mountainous area. The forest land area increased rapidly during 2010 2015 in R4 and R5. In 2000, the most of construction land was distributed in R3. Construction land expanded rapidly over time, constantly occupying arable land, gradually covered the entire R3 and expanding to the R4 in 2015. 


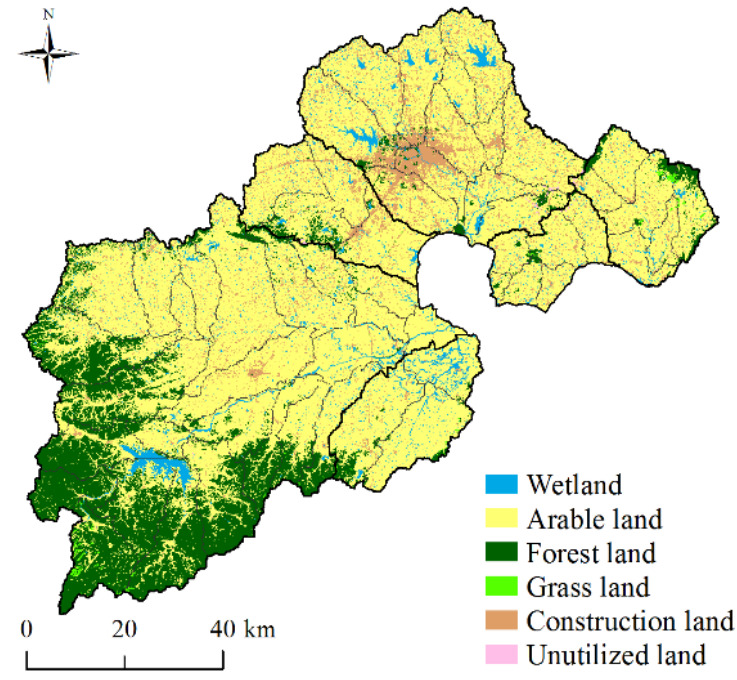

$\mathbf{a}$

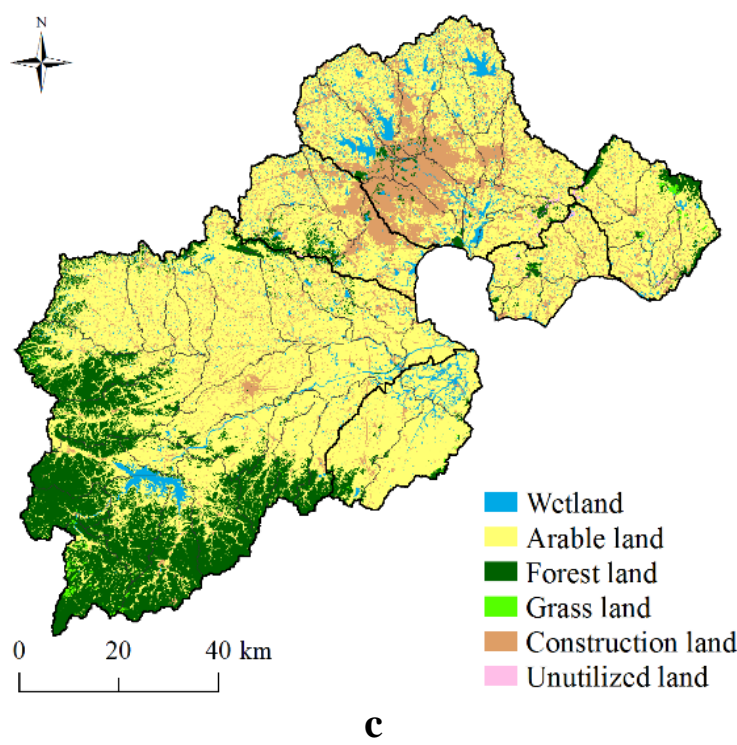

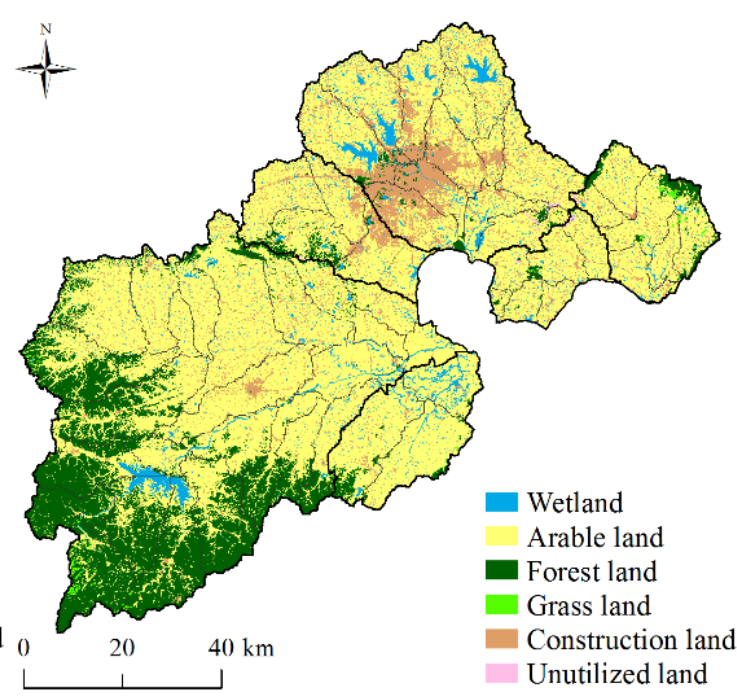

b

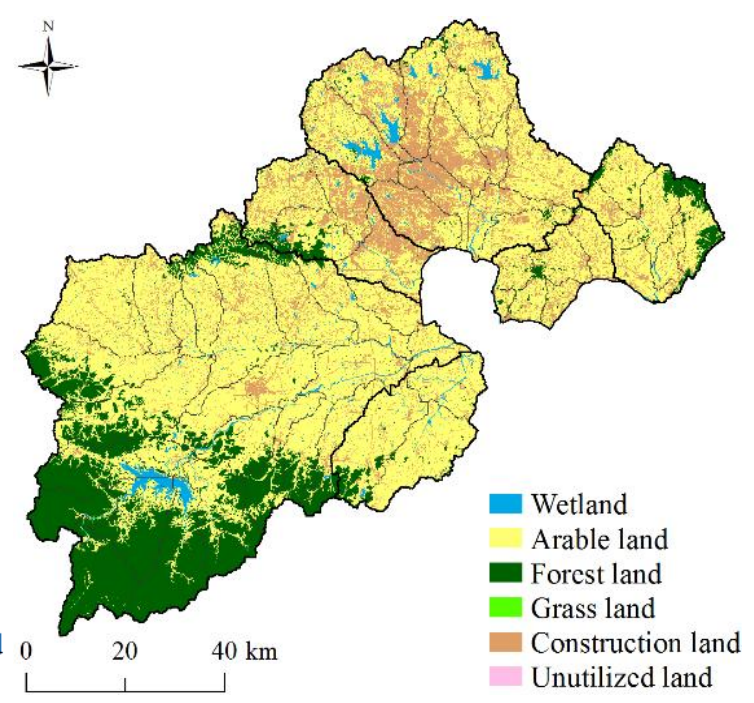

d

Figure 2. The tendency of land use/cover change (LUCC) over of each sub-basins. $\boldsymbol{a}$. 2000; $\boldsymbol{b}$. 2005; c. 2010; d. 2015

In addition to the spatial distribution characteristics of different land use types, the spatial structure and landscape characteristics also changed significantly with time. To show the change of land use structure and distribution in sub-basin, according to the landscape index changes over time to classify it into five types: (1) gradually increased (GI); (2) gradually decreased (GD)); (3) first increased and then decreased (ID); (4) first decreased and then increased (DI); (5) fluctuation type (FT). As shown in Figure 3, the land use patterns of most sub-basins were regular, and the sub-watersheds with exponential fluctuation are few.

The mainly type of change in CONTAG is GD. Except the sub-basin 20 is GI, the other sub-basins show the DI and FT characteristics, because the 20th sub-basin is the city center of Hefei, the land use types are mainly composed of construction land. In the latest decade, the construction land expands rapidly with urbanization process, so CONTAG showed a gradual increased trend. It is notable that half of the sub-basins in 
R3 show a trend of DI, because these sub-basins construction land expanded rapidly, the occupation of cultivated land has led to the decline of connectivity and advantage of cultivated land, so CONTAG decrease. In the later period, the cultivated land became the main land use type in the sub-basin, and the connectivity of construction land increased, so do the CONTAG increase.

The main types of FRAC are GI and DI. The land use pattern in the study area showed a tendency of fragmentation over time. In the six regions, all the sub-basins in $\mathrm{R} 1, \mathrm{R} 2$ and R4 showed a trend of DI, and the GI is mainly in the R5 region.

The trends of SHDI in each sub-basin were different. The sub-basins in the R1, R2 and R3 show the trend of ID, and the other sub-basins are GI and FT. Only 20 and 52 sub-basin are GD, because the 20 sub-basin is the city center of Hefei, construction land gradually replaced the other land use types, so SHDI showed a trend of GD, and 52th sub-basin forest area gradually increased to replace other land types, resulting in SHDI decreased.

The main change of SHEI was GI, few sub-basins showed the ID and FT characteristics. The distribution of different land use types in the study area were more uniform over time, and the dominant position of cultivated land was decreasing gradually.

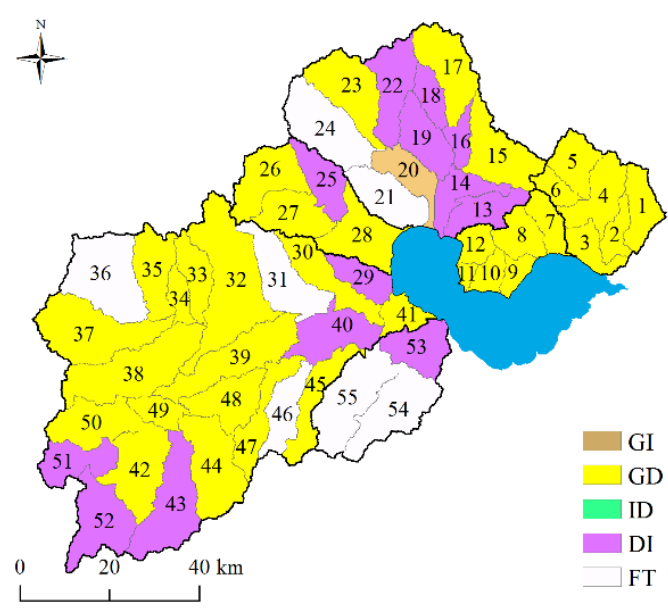

$\mathbf{a}$

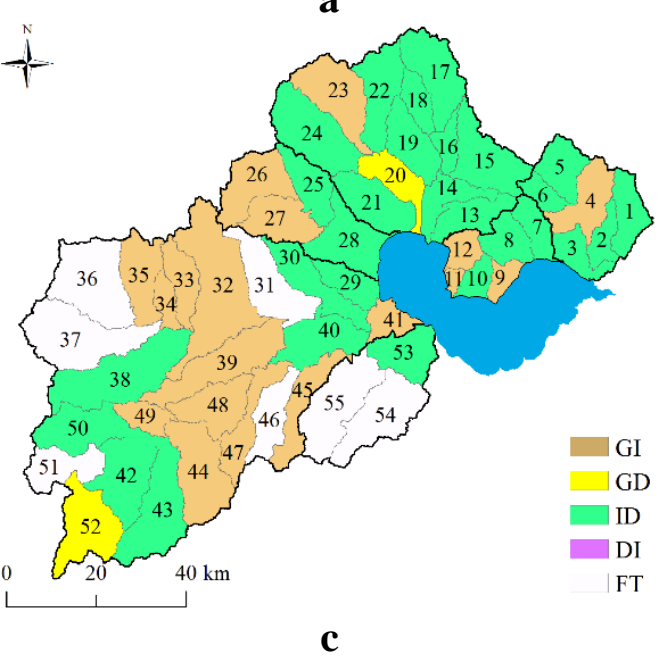

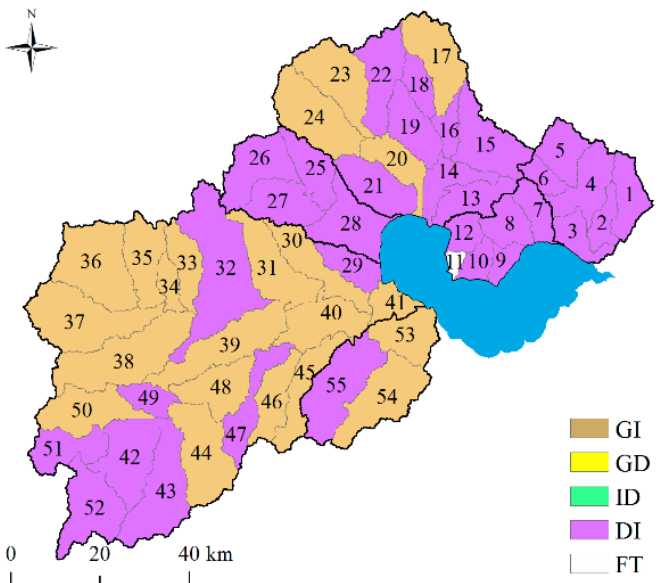

b

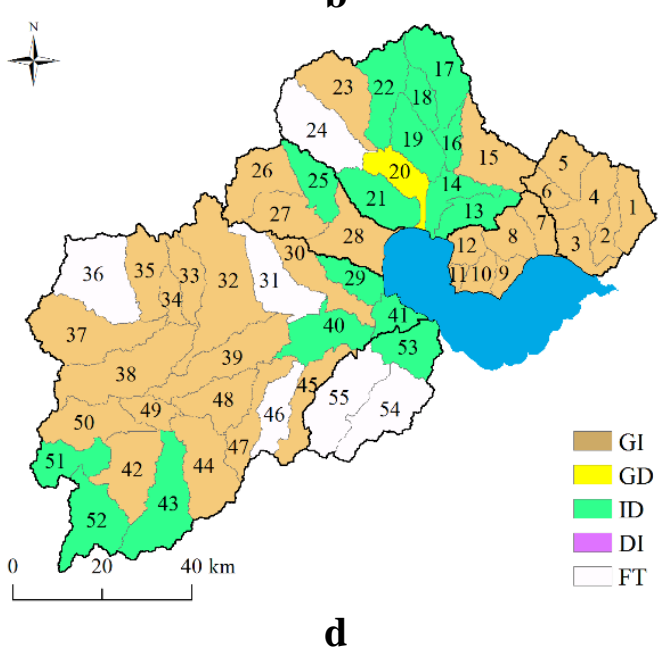

Figure 3. Landscape index changes in each sub-basin. a. CONTAG; b. FRAC; c. SHDI; d. 
The main land use types in Chaohu Lake Basin was AL, and the area of CL increased rapidly. The CONTAG was decreasing, and the FRAC and SHEI show an increasing trend.

\section{Characteristics of NPS P loads change}

According to SEDD model, 2000, 2005, 2010 and 2015 NPS P loads estimated. In order to analysis the NPS P loads intensity in each sub-basin, the 55 sub-basins NPS P loads intensity was divided into seven grades (Fig. 4). On the whole, the change of NPS P loads changes was not obvious from 2000 to 2005, part of sub-basins showed an increasing trend during 2005 2010, all sub-basins showed a rapid increase trend during 2010 2015. The most obvious change area is R5, the spatial distribution characteristics are obvious that the high loads area is concentrated in the southwest mountain area. In 2000, the NPS P loads was low, the highest value was $1.11 \mathrm{t} \cdot \mathrm{km}^{-2} \cdot \mathrm{yr}^{-1}$, and all the subbasins NPS P loads were below $40 \mathrm{~kg} \cdot \mathrm{km}^{-2} \cdot \mathrm{yr}^{-1}$, and nearly half of the sub-basins NPS $\mathrm{P}$ loads is less than $5 \mathrm{~kg} \cdot \mathrm{km}^{-2} \cdot \mathrm{yr}^{-1}$. In 2005 , the highest value is $1.67 \mathrm{t} \cdot \mathrm{km}^{-2} \cdot \mathrm{yr}^{-1}$, shows a slow increasing trend, most of the sub-basins NPS P loads change is not obvious, except No. 1, No. 3 and No. 4 sub-basin NPS P loads decreased in R1, No. 38, No. 47 and No. 50 sub-basin NPS P loads increased in R5. In 2010, the NPS P loads showed a rapid increase trend, the highest value reached $11.66 \mathrm{t} \cdot \mathrm{km}^{-2} \cdot \mathrm{yr}^{-1}$, NPS P loads changes is different in different sub-basins, 22th sub-basin is the only sub-basin with descending trend, nearly half of the sub-basins NPS P loads showed an increasing trend. In particular, No. 43, No. 44, No. 51 and No. 52 sub-basins NPS P loading in R5 showed a rapid upward trend, more than $100 \mathrm{~kg} \cdot \mathrm{km}^{-2} \cdot \mathrm{yr}^{-1}$. In 2015 , the highest value of the NPS $\mathrm{P}$ loads decreases to $5.42 \mathrm{t} \cdot \mathrm{km}^{-2} \cdot \mathrm{yr}^{-1}$, but most of the sub-basins NPS P loads present increased. A total of 22 sub-basins NPS P loads is higher than $20 \mathrm{~kg} \cdot \mathrm{km}^{-2} \cdot \mathrm{yr}^{-1}$. In addition, it is necessary to note that, when the most of the sub-basins in R5 are showing an increasing trend, especially after 2010 sub-basins NPS P loads is more than 100 $\mathrm{kg} \cdot \mathrm{km}^{-2} \cdot \mathrm{yr}^{-1}$ in the southwest, the No. 40 and No. 41 sub-basins NPS P loads remained below $5 \mathrm{~kg} \cdot \mathrm{km}^{-2} \cdot \mathrm{yr}^{-1}$.

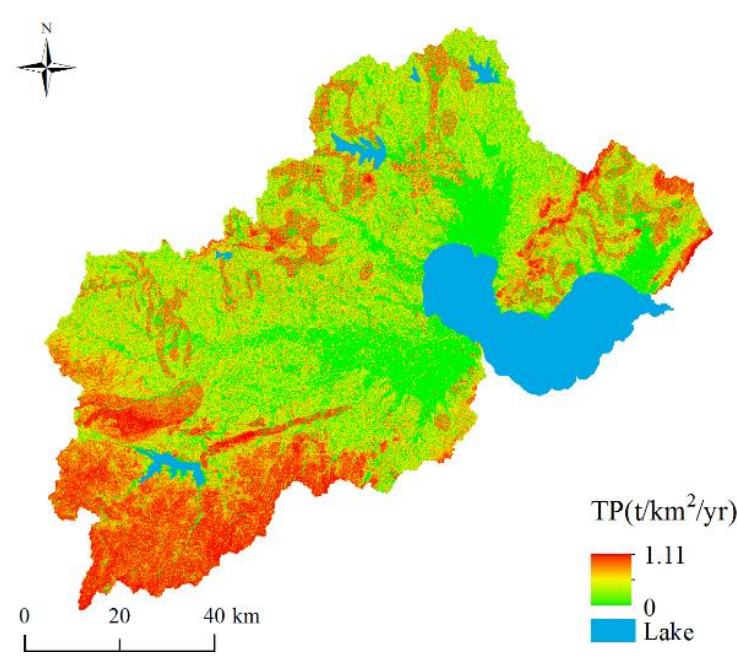

a

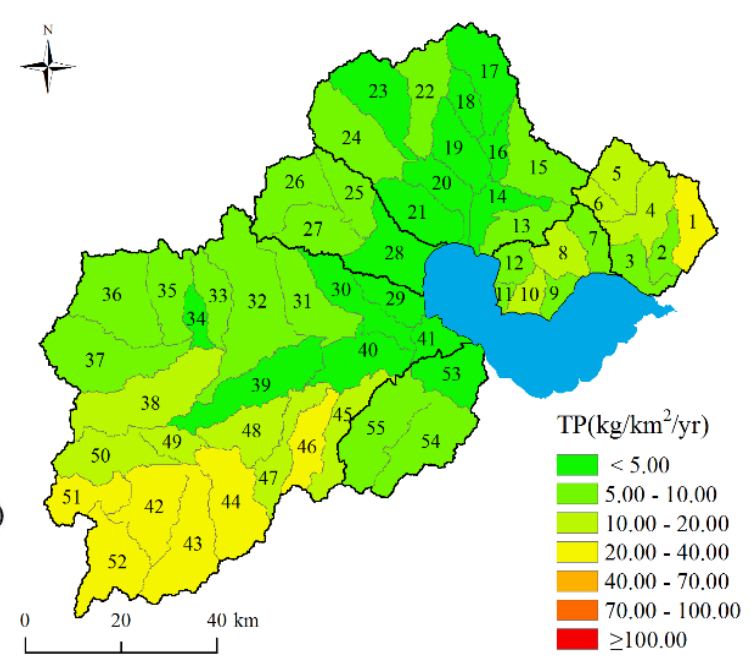

b 


$$
\text { - } 6229 \text { - }
$$

$+$
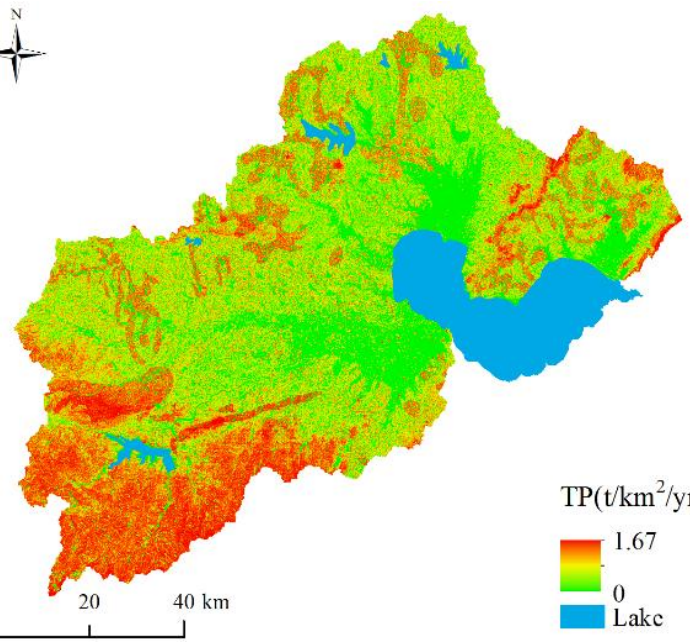

c
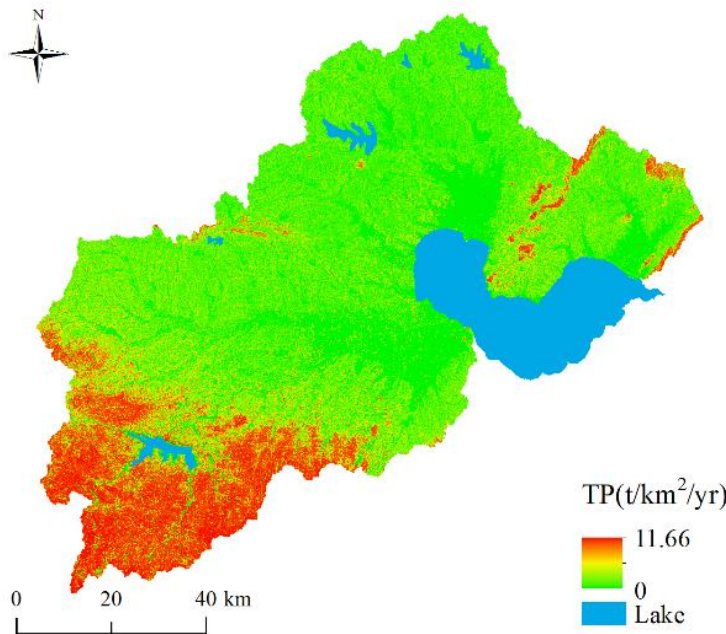

$\mathbf{e}$

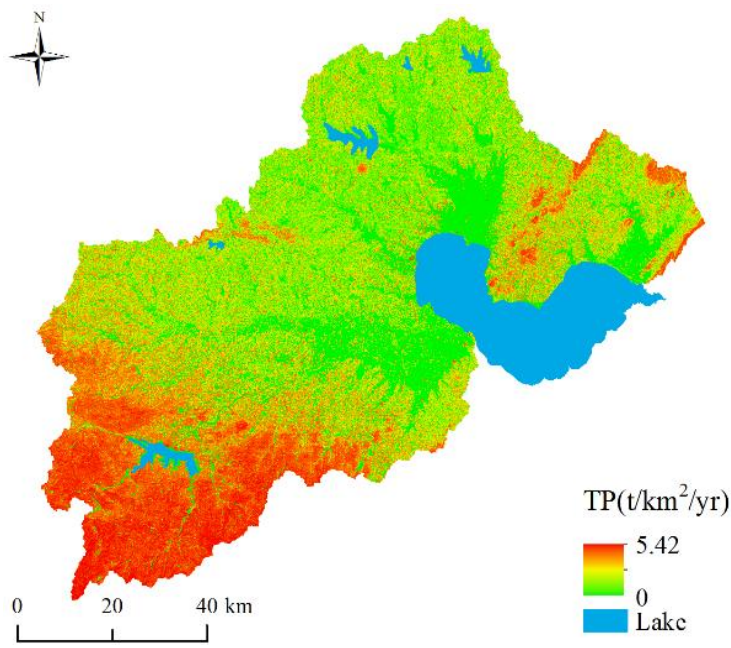

g

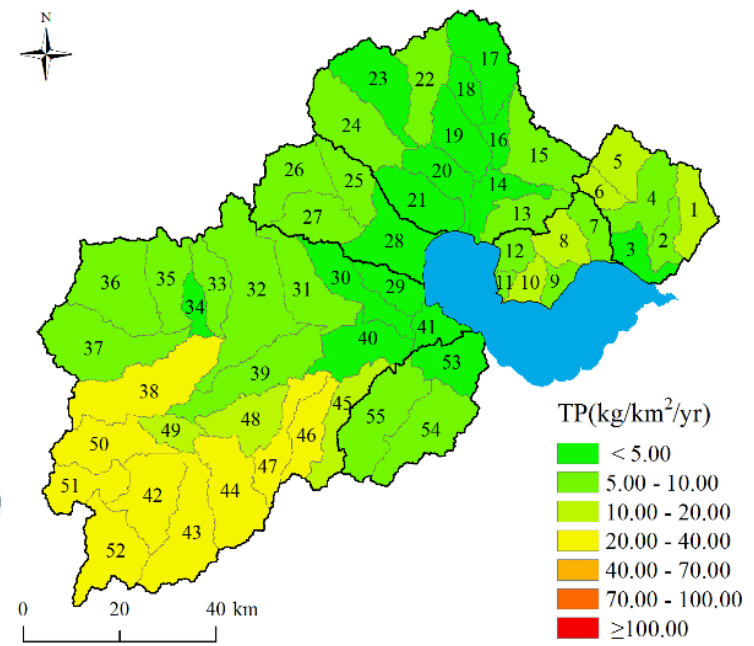

d

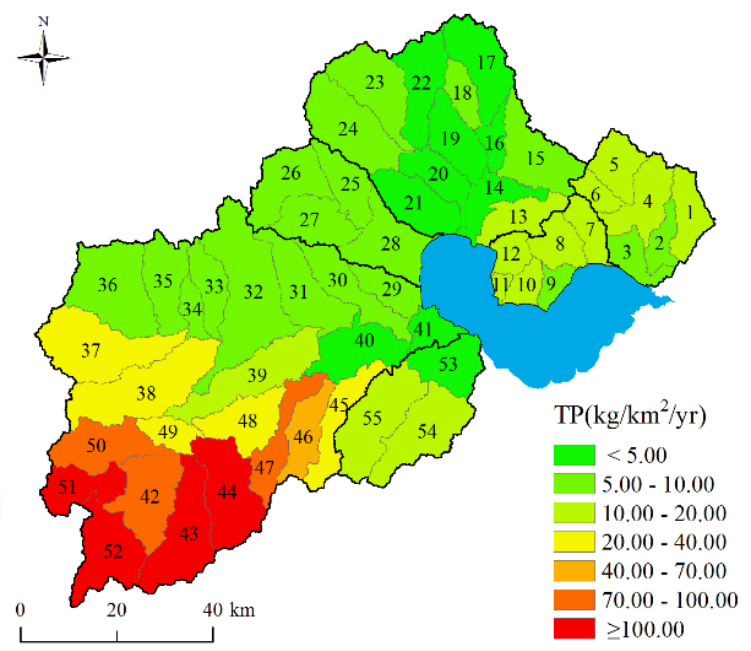

f

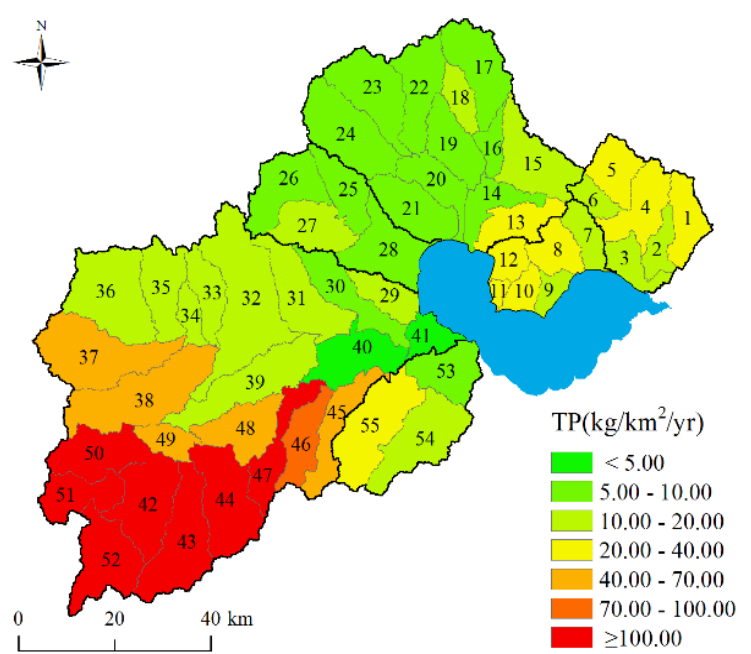

$\mathbf{h}$

Figure 4. The spatial distribution of NPS P loads. a. NPS P loads intensity in 2000; $\boldsymbol{b}$. each basin NPS P loads intensity in 2000; $c$. NPS P loads intensity in 2005; d. each basin NPS P loads intensity in 2005; $\boldsymbol{e}$. NPS P loads intensity in 2010; $\boldsymbol{f}$. each basin NPS P loads intensity in 2010; $\boldsymbol{g}$. NPS P loads intensity in 2015; $\boldsymbol{h}$. each basin NPS P loads intensity in 2015 
In summary, NPS P loads did not change significantly before 2005, and increased rapidly after 2005. The spatial distribution of the high loads zone was closely related to the terrain, so it concentrated in the southwest mountainous area.

\section{Relationship between NPS P loads and land use change}

The correlation coefficients between the NPS P loads and the different land use area and land use index in the whole study area and the six region are shown in Table 4.

On the whole, NPS P loads intensity was positively correlated with FL area and FRAC, negatively correlated with AL, CL and WL area. Verify the Jiang et al. (2014) conclusions on the cultivated land, construction land and forest land. The correlation coefficient of the whole study area was clear, but the correlation coefficients in each region were different. For example: (1) Although the NPS P loads was significantly positive correlated construction land area, but only in R5 was significantly positive correlated, and it was opposite in R2 and R6; (2) Although, on the whole, CONTAG, SHDI and SHEI were not significantly correlated with NPS P loads, there was a significant correlation in both R1 and R2.

Table 4. Correlation coefficients (r) between NPS P loads intensity and LUCC area and indices

\begin{tabular}{l|c|c|c|c|c|c|c|c|c|c}
\hline & FL & CL & GL & AL & WL & UL & CONTAG & FRAC & SHDI & SHEI \\
\hline All & $0.67^{* * *}$ & $-0.26^{* *}$ & 0.09 & $-0.14^{*}$ & $-0.56^{* *}$ & -0.09 & 0.13 & $0.56^{* *}$ & -0.11 & -0.09 \\
R1 & $0.80^{* *}$ & 0.04 & -0.09 & $-0.82^{* *}$ & $-0.78^{* *}$ & -0.31 & $-0.76^{* *}$ & $0.53^{* *}$ & $0.53^{* *}$ & $0.80^{*}$ \\
R2 & $0.47^{*}$ & $0.60^{* *}$ & -0.18 & $-0.68^{* *}$ & -0.15 & -0.26 & $-0.60^{* *}$ & $0.66^{* *}$ & $0.52^{* *}$ & $0.57^{*}$ \\
R3 & 0.19 & -0.12 &. & 0.18 & $-0.30^{*}$ & 0.27 & 0.10 & $0.38^{* *}$ & -0.12 & -0.15 \\
R4 & 0.40 & -0.04 & $-0.77^{* *}$ & -0.19 & $-0.72^{* *}$ & 0.19 & -0.46 & 0.29 & 0.16 & 0.38 \\
R5 & $0.63^{* *}$ & $-0.39^{* *}$ & 0.09 & $-0.63^{* *}$ & -0.07 & -0.10 & 0.06 & $0.69^{* *}$ & -0.04 & 0.00 \\
R6 & $0.69^{*}$ & $0.64^{*}$ & -0.17 & -0.14 & $-0.63^{*}$ &. & -0.24 & 0.49 & 0.26 & 0.26 \\
\hline
\end{tabular}

*Correlation is significant at the 0.05 level (2-tailed)

**Correlation is significant at the 0.01 level (2-tailed)

.${ }^{\mathrm{b}}$ indicates that there is no such land use type in this region

Some conclusions can be drawn from the simple correlation coefficient, but the relationship between the NPS P loads and the land use pattern cannot be generalized. There were differences in different regions, especially the relationship, in particular the relationship between the land area and NPS P loads.

\section{Discussion}

\section{Effects of land use change on NPS P loads in different regions}

The land use change statistics for the six regions are shown in Figure 5, AL was a major land use type in Chaohu Lake basin, and the second was followed by construction land. Except the R5, the region includes the Dabie Mountain, the FL area was larger than the CL area, become the second largest land area after cultivated land. Land. CL area showed an increasing trend in all basins, especially in R2, R3 and R4, CL area increased rapidly, AL area decreased rapidly, indicated that the expansion of construction land is based on the occupation of cultivated land. During 2000 2010, the 
wetlands in the six regions had different trends, such as R3 increased, while the R6 decreased, but during 2010 2015, WL area decreased in all regions. GL and UL area were small, almost replaced by other land in 2015

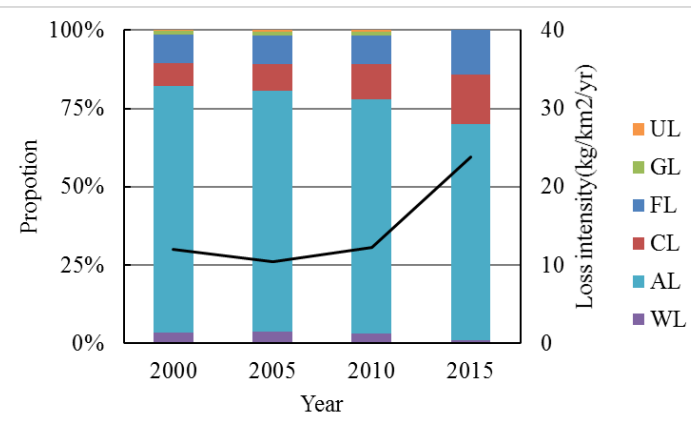

$\mathbf{a}$

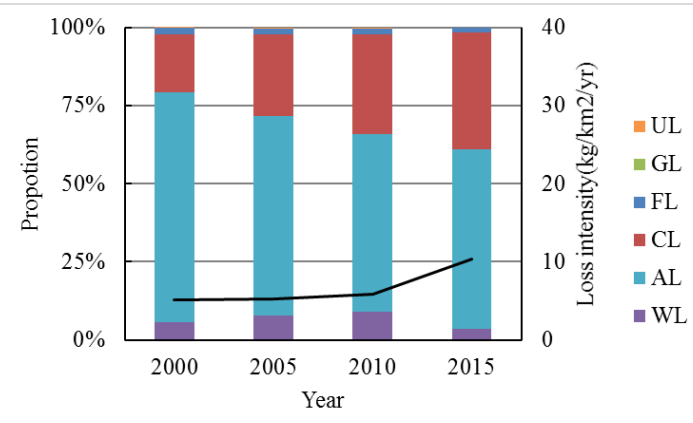

c

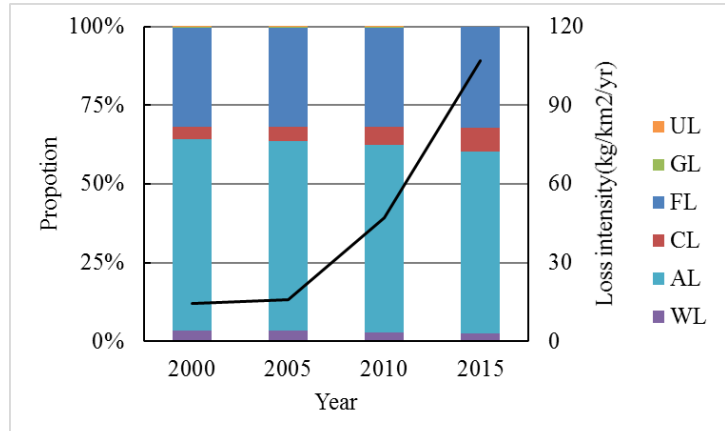

e

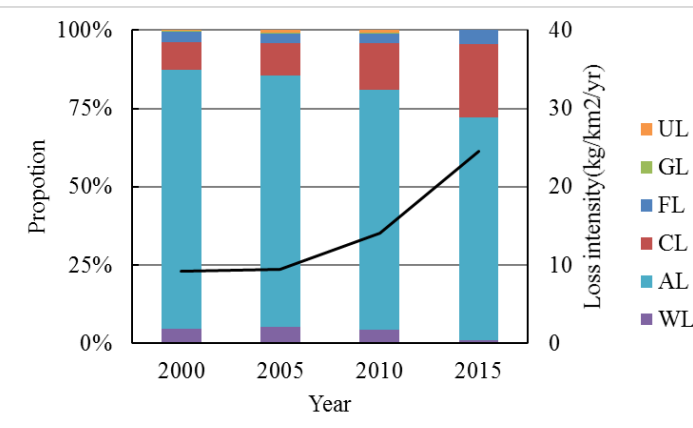

b

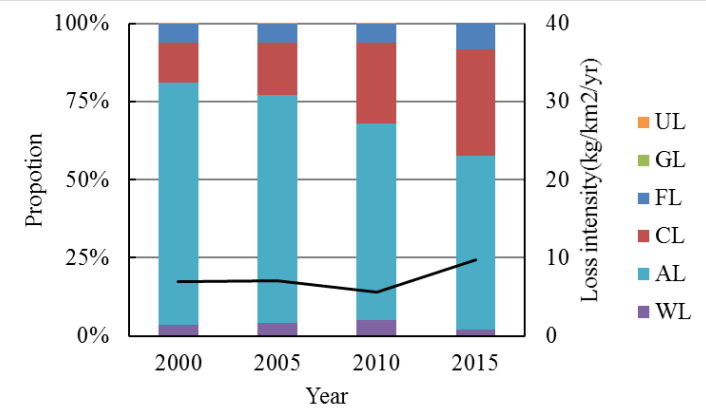

d

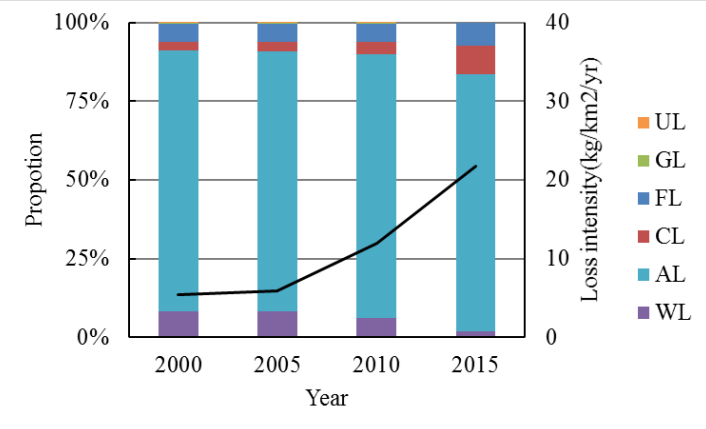

$\mathbf{f}$

Figure 5. Statistical data of each land use proportion and NPS P loss intensity in different region. a. $R 1 ;$ b. $R 2 ;$ c. $R 3$; d. $R 4$; e. $R 5 ; f . R 6$

NPS P loss intensity showed an increasing trend, the highest intensity areas in R5. During 2000 2005, NPS P loss intensity growth slowly. During 2005 2010, loss intensity increased rapidly, but the change is different in different regions, for example, in R5, NPS P loss intensity have trebled, while R4 is decreased. During 2010 2015, NPS P increased rapidly, the loss intensity in all regions have doubled. Chaohu Lake Basin NPS P loads estimation results are comparable with other scholars. On the spatial distribution, Jiang et al. (2014), calculated the three periods of Chaohu Lake Basin NPS P loads, the results of 2001 to 2008 show that the high value of NPS P is concentrated in the southwest mountainous area, and there is a small amount in the northeast, which is consistent with the results of this study. Wang et al. (2015) simulated the spatial 
distribution of NPS pollution in the Chaohu Lake Basin in 2010, and the spatial distribution of the NPS P loads was also the same. Kong et al. (2015) estimated the surface loads of the Chaohu basin from 1953 to 2012, NPS P loads are showing an increasing trend in 2000, 2000 and 2010 three periods, consistent with the trend of this research. Therefore, this study of NPS P loads estimation has a certain credibility.

During 2005 2010, R1 and R3 NPS P loads changed not obviously, R5 and R6 increased quickly, because the proportion of CL in R1 and R3 was significantly higher than that in R5 and R6, indicating that the CL can slow down the growth rate of the NPS P loads. During 2000 2010, NPS P loads intensity was not increasing in all regions, but during 2010 2015, all regions NPS P increased rapidly. During this period, the most obvious change of land use was the WL area decreased dramatically, illustrate the WL area was small, but played an important role in NPS P loads. This was consistent with the findings of Chescheir et al. (1992) and Braskerud (2002).

In summary, the WL and CL area had an important influence on the NPS P loads, WL area decreasing lead to NPS P loads intensity increase rapidly, the increase of CL area can slow down the growth rate of NPS P loads. On the other hand, FL and AL were not only the main land use types in the study area, but also the land classes that many scholars have paid attention to over the years. Therefore, we are going to discuss the effect of land use change on NPS P loads in WL, CL, FL and AL.

\section{Effects of land use change on NPS P loads in different land use types}

Because the proportion of WL area was small, and it had a very important impact on NPS P loads, so the WL was discussed separately. And the influence of WL area on the basin NPS P loads, as well as to the three main land use types NPS P loads. In recent years, many scholars have different opinions about the influence of AL, CL and FL on the NPS P loads (Jiang et al., 2014; Kim et al., 2016; Tasdighi et al., 2017). These three land use types are not only the main land use types in basin, but also would influence each other between the three land use types, so these three land use types are discussed together.

\section{Wetland}

According to Table 4, sub-basin was the evaluation unit, the correlation coefficient between WL area and NPS P loads is only 0.14, and not all regions have significant correlation. Taking the region as the evaluation unit, the NPS P loads intensity and WL area of 6 regions in 4 years were shown in Figure 6 . The results showed that the WL area was negatively correlated with the NPS P loads intensity, $\mathrm{R}^{2}$ was only 0.17 , and the highest point of the loads intensity belongs to the R5. When the 4 points in the R5 area were removed (Fig. 6b), R2 reached 0.55 . It indicated that there was a strong negative correlation between WL area and NPS P loads intensity, the change of WL area had a significant effect on the NPS P loads. In the R5, compared with other regions, the influence of WL area on the NPS P loads was different. As the area was affected by the mountain, the surface phosphorus loads intensity was significantly higher than other regions, causing the regional NPS P loads intensity beyond the adjustment ability of WL. On the other hand, it indicated that in different spatial scales, the WL area influence on NPS P loads approach was different, it still need further study in the future.

Table 5 is the correlation coefficient between WL area and the NPS P loads intensity of the three main land types. In the whole study area, the wetland area was negatively 
correlated with the NPS P loads intensity in AL, and there was no significant correlation with the other two land use types. However, there were differences in different areas and land use types. For example, in R1 and R6, WL area was significantly negative correlated with NPS P loads intensity in three land use types, but in R2 and R5, there was no significant correlation between WL area and NPS P in three land use types. It indicated that the change of WL area plays a role in the NPS P loads intensity in the whole area.

The WL area played an important role in NPS P loads intensity of the entire study area, and it was significantly negatively correlation with NPS P in AL, but the adjustment ability of the WL to NPS P loads was limited.

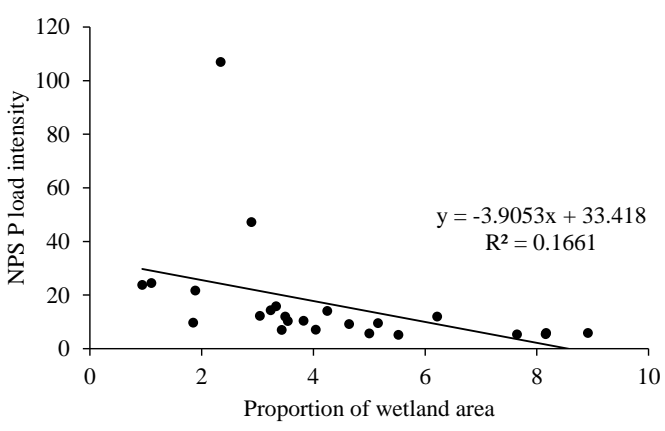

$\mathbf{a}$

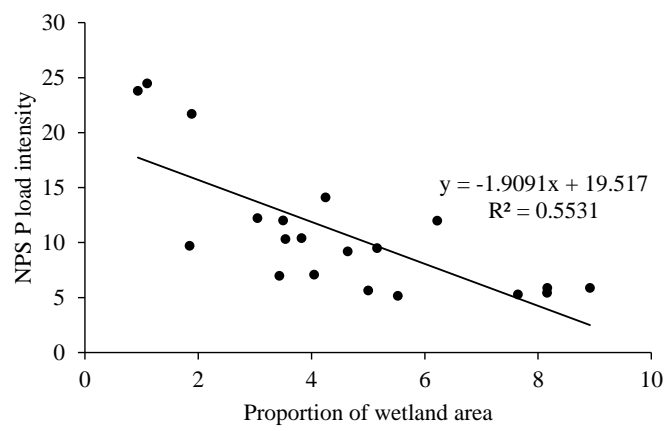

b

Figure 6. Relation between wetland area and NPS P loads intensity. $\boldsymbol{a}$. All regions and years; $\boldsymbol{b}$. remove $R 5$

Table 5. Correlation coefficient between the wetland area and different land NPS P loads intensity

\begin{tabular}{c|c|c|c|c|c|c|c}
\hline & Whole area & R1 & R2 & R3 & R4 & R5 & R6 \\
\hline $\mathrm{Al}$ & $-0.52^{* *}$ & $-0.85^{* *}$ & -0.17 & -0.27 & $-0.74^{* *}$ & -0.07 & $-0.67^{*}$ \\
$\mathrm{Cl}$ & -0.28 & $-0.78^{* *}$ & -0.33 & $-0.3^{*}$ & $-0.53^{*}$ & 0.02 & $-0.66^{*}$ \\
$\mathrm{Fl}$ & -0.34 & $-0.68^{* *}$ & 0.03 & -0.27 & -0.05 & -0.05 & $-0.69^{*}$ \\
\hline
\end{tabular}

*Correlation is significant at the 0.05 level (2-tailed)

**Correlation is significant at the 0.01 level (2-tailed)

\section{Arable land, construction land and forest land}

The correlation coefficients between the NPS P loads intensity and the land area and landscape index were calculated for each of the three land use types (Table 6). It can be seen that the effect of land use change on the NPS P loads in different land use types was very complicated.

(1) The NPS P loads intensity in different land use types were affected by FRAC in different degrees, and FRAC impact on NPS P loads intensity in AL is minimal. There were only three regions that the NPS P loads intensity in AL were significantly correlated with FRAC, and there were five regions that the NPS P loads intensity in FL were significant correlated with FRAC. And the correlation coefficient of FRAC and the loads intensity in R2 was the highest, reaching 0.83. (2) Among the three types of land use, the NPS P loads intensity in CL was most affected by its own area. Except R4, 
CL NPS P loads intensity in all regions were significantly correlated with its area, the highest correlation coefficient was 0.75. (3) Overall, three kinds of land NPS P loads intensities were positively correlated with FRAC, negatively correlated with CONTAG, which indicates that when the land use fragmentation was higher and the contagion was lower, the NPS P loads intensity was higher.

Table 6. Correlation coefficient of NPS P loads intensity and landscape index in three land use type

\begin{tabular}{c|c|c|c|c|c|c}
\hline Land use type & Region & Area & CONTAG & FRAC & SHDI & SHEI \\
\hline \multirow{5}{*}{ Al } & R1 & -0.04 & $-0.67^{* * *}$ & $0.73^{* *}$ & -0.01 & $0.59^{* *}$ \\
& R2 & -0.23 & $-0.55^{* *}$ & $0.55^{* *}$ & $0.5^{*}$ & $0.54^{* *}$ \\
& R3 & 0.23 & $0.38^{*}$ & 0.11 & $-0.33^{*}$ & $-0.4^{* *}$ \\
& R4 & -0.41 & 0.18 & -0.29 & -0.47 & -0.23 \\
& R5 & $-0.39^{* *}$ & -0.08 & $0.74^{* *}$ & 0.09 & 0.15 \\
& R6 & 0.48 & -0.5 & 0.17 & $0.66^{*}$ & 0.55 \\
\hline \multirow{5}{*}{ Cl } & R1 & $0.58^{* *}$ & $-0.69^{* *}$ & $0.59^{* *}$ & -0.02 & $0.6^{* *}$ \\
& R2 & $0.53^{* *}$ & $-0.51^{*}$ & $0.83^{* *}$ & 0.32 & $0.45^{*}$ \\
& R3 & $0.33^{*}$ & -0.2 & $0.52^{* *}$ & 0.06 & 0.15 \\
& R4 & 0.25 & -0.31 & 0.28 & -0.07 & 0.23 \\
& R5 & $-0.32^{* *}$ & -0.1 & $0.64^{* *}$ & 0.15 & 0.16 \\
& R6 & $0.75^{* *}$ & -0.32 & 0.24 & 0.47 & 0.36 \\
\hline \multirow{5}{*}{ F1 } & R1 & 0.02 & $-0.8^{* *}$ & $0.62^{* *}$ & 0.34 & $0.76^{* *}$ \\
& R2 & 0.27 & $-0.64^{* * *}$ & $0.78^{* *}$ & $0.49^{*}$ & $0.6^{* *}$ \\
& R3 & 0.02 & -0.04 & $0.43^{* *}$ & -0.08 & -0.03 \\
& R4 & -0.14 & -0.46 & $0.53^{*}$ & 0.1 & 0.35 \\
& R5 & $0.52^{* *}$ & 0 & $0.68^{* *}$ & 0.03 & 0.06 \\
& R6 & $0.67^{*}$ & -0.42 & 0.19 & $0.58^{*}$ & 0.46 \\
\hline
\end{tabular}

*Correlation is significant at the 0.05 level (2-tailed)

**Correlation is significant at the 0.01 level (2-tailed)

In R5, three land use types NPS P loads intensities were significantly correlated with the corresponding land area. Moreover, only in R5, the CL area negatively correlated with its NPS P loads intensity, and the NPS P loads intensity of the R5 region was hardly affected by the WL area (Table 5). This indicated that the NPS P load in mountainous area was mainly affected by terrain. In this case, the change of human activities on soil properties, and the blocking effect of artificial surface on rainfall erosion can lead to the decrease of NPS P load. Therefore, the effect of land use on NPS P load in mountainous and plain was different. In the future research, it is necessary to explore the mechanism of phosphorus loss in different slope conditions. In contrast to previous scholars' conclusions (Catherine et al., 2013; Tang et al., 2005), human activity does not only exacerbate the NPS P loads. In plain areas, human activities lead to NPS P loads intensity increased, while in mountainous areas, terrain plays a dominant role in NPS P loads intensity, human activities can reduce the NPS P loads.

In conclusion, three land use types, NPS P loads intensity in AL was the least affected by FRAC, NPS P loads intensity in CL was affected by its own area change most significantly. Human activities in the mountains may reduce the NPS P loads intensity. 


\section{Conclusion}

In this study, six main natural rivers basin into the Chaohu Lake were chosen as the study area. The SEDD model was used to estimate the NPS P loads from 2000 to 2015, and a variety of typical land use types were selected to analyze the relationship between NPS P loads and land use change pattern, in order to explore the impact mechanism of land use on NPS P loads. The conclusions are:

(1) The NPS P loads intensity was positively correlated with FL area, and negatively correlated with AL, CL and WL area, and positively correlated with FRAC.

(2) Although the WL area was small, it played an important role in the NPS P loads in the basin, the WL area was significantly negative correlated with the NPS P loads intensity in AL. But its ability to adjust the NPS P loads was limited.

(3) Compared with AL, NPS P loads intensities of FL and CL were more susceptible to FRAC. The NPS P loads intensity of CL was more susceptible to its own area.

Land use patterns have an important impact on lake water quality through the impact of NPS pollution. Combining the basin and lake as a whole and analyzing the mechanism between land use, NPS pollution and lake water quality will be the focus of future research.

Acknowledgements. This work was funded by the National Natural Science Foundation of China (41671284). Acknowledgement for the data support from "Lake-Watershed Science Data Center, National Earth System Science Data Sharing Infrastructure, National Science \& Technology Infrastructure of China. (http://lake.geodata.cn)". Land use data supported by the "Strategic Priority Research Program - Climate Change: Carbon Budget and Related Issues" of the Chinese Academy of Sciences, Grant No. XDA05050106.

\section{REFERENCES}

[1] Ahearn, D. S., Sheibley, R. W., Dahlgren, R. A., Anderson, M., Johnson, J., Tate, K. W. (2005): Land use and land cover influence on water quality in the last free-flowing river draining the western Sierra Nevada, California. - J Hydrol 313(3-4): 234-247.

[2] Bechmann, M., Stalnacke, P., Kvoerno, S., Eggestad, H. O., Oygarden, L. (2009): Integrated tool for risk assessment in agricultural management of soil erosion and losses of phosphorus and nitrogen. - Sci Total Environ 407(2): 749-759.

[3] Bingner, R. L., Theurer, F. D., Yuan, Y. (2003): AnnAGNPS Technical Processes. USDA-ARS. National Sedimentation Laboratory, Oxford, MS.

[4] Borrelli, P., Marker, M., Panagos, P., Schutt, B. (2014): Modeling soil erosion and river sediment yield for an intermountain drainage basin of the Central Apennines, Italy. Catena 114: 45-58.

[5] Braskerud, B. C. (2002): Factors affecting nitrogen retention in small constructed wetlands treating agricultural non-point source pollution. - Ecol Eng 18(3): 351-370.

[6] Bu, K., Zhang, S. W., Yan, Y. C., Wang, W. J., Zhang, Y. B. (2008): Soil erosion change characteristic of different watersheds of Sanjiang Plain during the past 50 years. Scientia Geographica Sinica 28(3): 361-368.

[7] Bu, Z., Yang, L., Bu, Y., Wu, J. (2002): Soil erodibility (K) value and its application in Taihu lake catchment. - Acta Pedologica Sinica 39(3): 296-300.

[8] Cai, C., Ding, S., Shi, Z., Huang, L., Zhang, G. (2000): Study of applying USLE and geographical information system IDRISI to predict soil erosion in small watershed. Journal of Soil and Water Conservation 14(2): 19-24. 
[9] Catherine, A., Mouillot, D., Maloufi, S., Troussellier, M., Bernard, C. (2013): Projecting the impact of regional land-use change and water management policies on lake water quality: an application to periurban lakes and reservoirs. - Plos One 8(8).

[10] Chescheir, G. M., Skaggs, R. W., Gilliam, J. W. (1992): Evaluation of wetland buffer areas for treatment of pumped agricultural drainage water. - T Asae 35(1): 175-182.

[11] Delpla, I., Baures, E., Jung, A. V., Thomas, O. (2011): Impacts of rainfall events on runoff water quality in an agricultural environment in temperate areas. - Sci Total Environ 409(9): 1683-1688.

[12] Dong, G., Yang, S., Gao, Y., Bai, J., Wang, X., Zheng, D. (2014): Spatial evaluation of phosphorus retention in riparian zones using remote sensing data. - Environ Earth Sci 72(5): 1643-1657.

[13] El-Khoury, A., Seidou, O., Lapen, D. R., Que, Z., Mohammadian, M., Sunohara, M., Bahram, D. (2015): Combined impacts of future climate and land use changes on discharge, nitrogen and phosphorus loads for a Canadian river basin. - J Environ Manage 151: 76-86.

[14] Fu, G., Chen, S., McCool, D. K. (2006): Modeling the impacts of no-till practice on soil erosion and sediment yield with RUSLE, SEDD, and ArcView GIS. - Soil and Tillage Research 85(1): 38-49.

[15] Garnier, M., Lo Porto, A., Marini, R., Leone, A. (1998): Integrated use of GLEAMS and GIS to prevent groundwater pollution caused by agricultural disposal of animal waste. Environ Manage 22(5): 747-756.

[16] Haggard, B. E., Storm, D. E., Tejral, R. D., Popova, Y. A., Keyworth, V. G., Stanley, E. H. (2001): Stream nutrient retention in three Northeastern Oklahoma agricultural catchments. - T Asae 44(3): 597-605.

[17] Hoffmann, C. C., Kjaergaard, C., Uusi-Kamppa, J., Hansen, H. C. B., Kronvang, B. (2009): Phosphorus retention in Riparian buffers: review of their efficiency. - J Environ Qual 38(5): 1942-1955.

[18] Hollis, G. (1975): The effect of urbanization on floods of different recurrence interval. Water Resources Research 11(3): 431-435.

[19] Hundecha, Y., Bardossy, A. (2004): Modeling of the effect of land use changes on the runoff generation of a river basin through parameter regionalization of a watershed model. - J Hydrol 292(1): 281-295.

[20] Jiang, T., Huo, S., Xi, B., Su, J., Hou, H., Yu, H., Li, X. (2014): The influences of landuse changes on the absorbed nitrogen and phosphorus loadings in the drainage basin of Lake Chaohu, China. - Environ Earth Sci 71(9): 4165-4176.

[21] Kim, D. K., Kaluskar, S., Mugalingam, S., Arhonditsis, G. B. (2016): Evaluating the relationships between watershed physiography, land use patterns, and phosphorus loading in the bay of Quinte basin, Ontario, Canada. - J Great Lakes Res 42(5): 972-984.

[22] Kim, J., Choi, J., Choi, C., Park, S. (2013): Impacts of changes in climate and land use/land cover under IPCC RCP scenarios on streamflow in the Hoeya River Basin, Korea. - Sci Total Environ 452: 181-195.

[23] Kong, X., Dong, L., He, W., Wang, Q., Mooij, W. M., Xu, F. (2015): Estimation of the long-term nutrient budget and thresholds of regime shift for a large shallow lake in China. - Ecol Indic 52: 231-244.

[24] Li, H., Yang, G., Liu, X., Li, J. (2008): Response of non-point pollution output to landuse change and management strategy in Lihe River watershed of Taihu Lake Basin. - Journal of Natural Disasters 1: 027.

[25] Lin, C., He, M., Zhou, Y., Guo, W., Yang, Z. (2008): Distribution and contamination assessment of heavy metals in sediment of the Second Songhua River, China. - Environ Monit Assess 137(1): 329-342.

[26] Lin, C., Ma, R., Su, Z., Zhu, Q. (2015): Detection of critical LUCC indices and sensitive watershed regions related to lake algal blooms: a case study of Taihu Lake. - Int J Env Res Pub He 12(2): 1629-1648. 
[27] Lin, C., Wu, Z., Ma, R., Su, Z. (2016): Detection of sensitive soil properties related to non-point phosphorus pollution by integrated models of SEDD and PLOAD. - Ecol Indic 60: 483-494.

[28] McGarigal, K., Marks, B. J. (1995): FRAGSTATS: Spatial Pattern Analysis Program for Quantifying Landscape Structure. General Technical Report PNW-GTR-351. - U.S. Department of Agriculture, Forest Service, Pacific Northwest Research Station, Portland, OR.

[29] Naramngam, S., Tong, S. T. Y. (2013): Environmental and economic implications of various conservative agricultural practices in the Upper Little Miami River basin. - Agr Water Manage 119: 65-79.

[30] Norton, L., Elliott, J. A., Maberly, S. C., May, L. (2012): Using models to bridge the gap between land use and algal blooms: An example from the Loweswater catchment, UK. Environ Modell Softw 36: 64-75.

[31] Onyando, J. O., Kisoyan, P., Chemelil, M. C. (2005): Estimation of potential soil erosion for River Perkerra catchment in Kenya. - Water Resour Manag 19(2): 133-143.

[32] Ouyang, W., Huang, H., Hao, F., Guo, B. (2013): Synergistic impacts of land-use change and soil property variation on non-point source nitrogen pollution in a freeze-thaw area. J Hydrol 495: 126-134.

[33] Pan, B., Yi, W., Wang, X., Qin, H., Wang, J., Qiao, Y. (2011): Inversion of the lake total nitrogen concentration by multiple regression kriging model based on hyperspectral data of HJ-1A. - Spectrosc Spect Anal 31(7): 1884-1888.

[34] Recanatesi, F., Ripa, M. N., Leone, A., Luigi, P., Luca, S. (2013): Land use, climate and transport of nutrients: evidence emerging from the lake vicocase study. - Environ Manage 52(2): 503-513.

[35] Shang, G., Shang, J. (2007): Spatial and temporal variations of eutrophication in western Chaohu Lake, China. - Environ Monit Assess 130(1): 99-109.

[36] Sharpley, A. N., Williams, J. R. (1990): EPIC, Erosion/Productivity Impact Calculator. Technical Bulletin, USDA, Washington, DC.

[37] Stefano, C. D., Ferro, V. (2007): Evaluation of the SEDD model for predicting sediment yield at the Sicilian experimental SPA2 basin. - Earth Surface Processes and Landforms 32(7): 1094-1109.

[38] Taguas, E. V., Moral, C., Ayuso, J. L., Perez, R., Gomez, J. A. (2011): Modeling the spatial distribution of water erosion within a Spanish olive orchard microcatchment using the SEDD model. - Geomorphology 133(1-2): 47-56.

[39] Tang, Z., Engel, B. A., Pijanowski, B. C., Lim, K. J. (2005): Forecasting land use change and its environmental impact at a watershed scale. - J Environ Manage 76(1): 35-45.

[40] Tasdighi, A., Arabi, M., Osmond, D. L. (2017): The relationship between land use and vulnerability to nitrogen and phosphorus pollution in an urban watershed. - J Environ Qual 46(1): 113-122.

[41] Wang, S., Dou, H. (1998): Chinese Lakes. - Science Press, Beijing.

[42] Wang, S., Jiang, X., Jin, X. (2011): Classification and pollution characteristic analysis for inflow rivers of Chaohu Lake. - Environmental Science 32(10): 2834-2839.

[43] Wang, X., Wang, Q., Wu, C., Liang, T., Zheng, D., Wei, X. (2012): A method coupled with remote sensing data to evaluate non-point source pollution in the Xin'anjiang catchment of China. - Sci Total Environ 430: 132-143.

[44] Wang, X., Wang, X., Zhu, L., Ma, Y., Wu, C., Wang, Q., Feng, A., Chen, M. (2015): Spatial analysis on diffuse pollution and algal bloom characteristic with remote sensing in Chao Lake Basin. - China Environmental Science 35(5): 1511-1519.

[45] Wilson, C. O., Weng, Q. (2011): Simulating the impacts of future land use and climate changes on surface water quality in the Des Plaines River watershed, Chicago Metropolitan Statistical Area, Illinois. - Sci Total Environ 409(20): 4387-4405. 
[46] Wu, C., Li, S., Ren, H., Yao, X., Huang, Z. (2012a): Quantitative estimation of vegetation cover and management factor in USLE and RUSLE models by using remote sensing data: a review. - The Journal of Applied Ecology 23(6): 1728-1732.

[47] Wu, L., Long, T., Liu, X., Guo, J. (2012b): Impacts of climate and land-use changes on the migration of non-point source nitrogen and phosphorus during rainfall-runoff in the Jialing River Watershed, China. - J Hydrol 475: 26-41.

[48] Xu, L., Xu, X., Meng, X. (2013): Risk assessment of soil erosion in different rainfall scenarios by RUSLE model coupled with Information Diffusion Model: A case study of Bohai Rim, China. - Catena 100: 74-82.

[49] Yan, W., Wang, X. (1998): Preliminary study on non3point sources pollution in the Chaohu Lake drainage basin. - Scientia Geographica Sinica 18(3): 263 r267.

[50] Yang, M., Li, X., Hu, Y., He, X. (2012): Assessing effects of landscape pattern on sediment yield using sediment delivery distributed model and a landscape indicator. Ecol Indic 22: 38-52.

[51] Zhang, K., Peng, W., Yang, H. (2007): Soil erodibility and its estimation for agricultural soils in China. - Acta Pedologica Sinica 44(1): 7-13.

[52] Zhou, H., Gao, C. (2011): Assessing the risk of phosphorus loss and identifying critical source areas in the Chaohu Lake watershed, China. - Environ Manage 48(5): 1033-1043.

[53] Zhou, W., Wu, B. (2008): Assessment of soil erosion and sediment delivery ratio using remote sensing and GIS: a case study of upstream Chaobaihe River catchment, north China. - Int J Sediment Res 23(2): 167-173. 